\title{
MAKING RESEARCH A PART OF THE PUBLIC AGENDA
}

\author{
George E. Walker \\ Vice President for Research \\ and Dean of the Graduate School \\ Indiana University
}

\section{Introduction}

It is a pleasure to be with you at this year's Merrill Summer Conference. Since this is a working, interactive conference, I will try to present my remarks in a way that will stimulate later discussion and new ideas.

First of all, let's assume that those of us here today are a group made up of representatives from research universities or from federal, state, or private sector organizations. Let's assume also that we have fairly extensive knowledge about research universities and the potential of their research-educated students and faculty to make important contributions to the quality of life of citizens, start new businesses and enhance existing businesses, promote economic development, attract new companies (and hence jobs and tax base to individual states), and so forth.

Let us further assume that each of our institutions currently has experience partnering with industry and has already produced papers (distributed to appropriate stakeholders) that highlight the importance of research carried out on our campuses, and that these informational materials have been used to educate the state legislature, industry, boards of regents or trustees, and the general public.

Moreover, let's assume that each of the institutions represented here has active state and federal relations efforts to coordinate outreach with government agencies and legislatures, and an office (often the vice president for research or an arm's length foundation) to coordinate activities with industry. Probably the president's or chancellor's office coordinates activities involving boards of regents or trustees, alumni, a state higher education commission, and research promotion, perhaps with the help of a vice president for external affairs and a director of alumni relations. 
Establishing vigorous, informed, cooperative efforts that promote the value of university research in all of these areas is a crucial first step that I will assume the institutions represented here have already taken $\nabla$ but I will make some suggestions regarding strengthening and broadening these efforts.

My presumption is that you all agree with me that in terms of support, respect, and priority setting, university research is not yet where it needs to be on the public agenda. What we need to do is discuss additional steps we can take to strengthen research as a multifaceted benefit to society and therefore an essential part of the public agenda.

In my remarks, I will not quote statistics showing the benefits of research to stakeholders, although we need to use the quantitative measures and studies that are available. My comments will be divided into four parts:

I. Background: Some simple questions whose answers may guide our discussion

II. Practices that we have initiated in the past few years at Indiana University

III. Successes and suggestions

IV. Questions for future consideration and discussion.

\section{Background}

\section{General Comments}

The future belongs to those who can forcefully cooperate and meet important goals of the agenda setters. Success requires a long-term initiative that must be consistent, must survive the accountability/ assessment test, and must avoid pitting different research institutions against each other $\nabla$ and avoid pitting major stakeholders against each other. The efforts we make must be sincere. Success can be achieved through these means, and is being achieved every day at many research institutions. To use the example of my own institution, at Indiana University external grants and contracts funding will increase by nearly $\$ 100$ million this year.

But how exactly does this kind of success come about? 
First, let's examine the role of faculty in bringing the research agenda to the public. Faculty members can play a vital role in advocating the importance of research because of their infectious enthusiasm and indepth knowledge of their discipline. However, not all faculty are effective spokespersons for research and, quite frankly, not all research is going to be highly valued by a given public. We have to know what "sells" and focus on that. Let me quickly say, though, that this approach carries a caveat: we need to be alert to faculty backlash. Some faculty members may complain that certain research (particularly research of obvious direct importance to industry and economic development) gets too much attention, to the detriment of other research, teaching, and the academic mission in general. It's very important that there be appropriate hope in all disciplines. Good faculty morale is essential, and a sense of cooperation and interdependence contributes strongly to that. To offer again an illustration from Indiana University, the interdependence of research success across departments is highlighted by the fact that the humanities research centers care about the funding health of the Indiana University Cyclotron Facility $\nabla$ they know that "resources" generated by the Cyclotron are a significant source of funding for their own centers.

Now, here are a few preliminary, background questions that are important to address before we can fully understand the task of promoting the research mission of our universities:

1. Who is the public?

2. How does the public rate the importance of university research?

2. How do we know how the public rates research?

4. Why do we care?

5. Why do we need to pay special attention to research and research support?

6. How do we act when we make choices internally to support research?

1. Who is the public?

From a university's standpoint, the public may be said to include citizens; federal, state, and community elected and appointed officials; industries; university donors and alumni; and students and parents. 
2. How does the public rate the importance of university research?

The public sees the benefits of research, but also suspects that research takes away from teaching and learning. In other words, the public has mixed views on the value of university research.

3. How do we know how the public rates research?

There are numerous marketing studies germane to the issue. Also, we can tell a lot from the actions and public statements of the various organizations and persons who have a stake in university research.

\section{Why do we care?}

We must care how the public feels about research because only with that attitude can we begin to improve the current situation, and establish university research as a high priority on the public agenda.

5. Why do we need to pay special attention to research and research support?

Answers to this may seem obvious, but let's take a look at them: Research is a major part of our mission. It facilitates learning-through the inspiration of teachers who are working at the forefront of knowledge and who bring their excitement into the classroom, and through the opportunity for students to become involved in research themselves. It provides many services to the state. It is essential to attracting and retaining outstanding faculty. It is crucial to the prestige of our universities. And, arguably, it is a significant financial resource for the university.

6. How do we act when we make choices internally to support research?

These are the actions we should bring into focus: First, we need to build on the faculty strengths we already have. Second, we must make the best use of our academic environment and administrative decisions to attract and retain outstanding faculty. Third, we need to build strength in areas that we have reason to think will be supported nationally. And fourth, we must ensure that state organizations and industry have genuine opportunities to provide input into our decisions regarding research $\nabla$ before we go to them for resources.

II. Recent Initiatives at Indiana University

If you've already been singing a long time and you wish to sing better, you most often have to go back to the basics; for example, you may have to learn to breathe differently and develop stronger and more 
disciplined breath support. If we want research to be a higher priority in the public sector, we not only have to present the positive arguments for research support, but we have to eliminate the perceived negatives and get the energetic support of members of the public to be our spokespersons. These members of the public can include undergraduates, citizen groups, industry, entrepreneurs, and powerful members of the legislative and executive branches. I would also include the trustees in this group. The university president's strong leadership, vision, and dedication to creating the right environment for the support of research is absolutely essential.

I'll mention here a few initiatives that Indiana University and other institutions have taken along these lines.

\section{a. Programs for Undergraduates}

1. President's Summer Undergraduate Research Initiative. This program is a widely available opportunity for undergraduate research using graduate students and faculty as mentors, and including opportunities to attend national conferences to report the research results.

We believe that in the future there will be increased funding from federal agencies for undergraduate research (which is tied in with the graduate student learning experience), and we intend to compete strongly for these funds.

2. Scholarship of Teaching. This faculty initiative supports and publicizes research and scholarship on teaching. "Scholarship" implies a reflective habit of mind; and in keeping with that outlook, this initiative is designed to improve disciplinary research as well as provide insights into teaching.

3. Marketing Strategy. A marketing strategy should be a cohesive set of efforts that will convince students that the prestige of the institution depends significantly on research, and that research of high quality therefore increases the value of their degree.

As a result of our marketing strategy over the past few years, Indiana University's undergraduate students have specifically requested that their tuition be increased an additional one percent, with that money being invested in hiring additional faculty to both teach and do research. The students monitor how this additional money is spent.

Undergraduates are excellent representatives to the trustees and to federal and state offices on the role of research in creating a more fertile learning environment. 


\section{b. Graduate Students}

You may believe that graduate student support is a given and that no special efforts are needed for graduate students to be enthusiastic supporters of additional funds for research. I find that this is not entirely true. It is clear in the national news, and probably your experience as well as mine, that there are important issues to be addressed, involving faculty mentoring, training of graduate students as teachers, and fair compensation. The competitiveness of today's job market and special efforts to make students more successful in that market also are very important factors.

Initiatives we have used to earn graduate student trust and generate enthusiasm include day care; health insurance; a graduate placement center; a strengthened Graduate Student Organization (GSO); participation in the national Preparing Future Faculty program sponsored by the Pew Charitable Trusts, the Association of American Colleges and Universities, and the Council of Graduate Schools; more representation in faculty governance; and a graduate student presence on key university committees.

The GSO meets once or twice a year with the Board of Trustees to communicate their concerns and our successes. This has been an important and positive experience for both the Trustees-in their commitment of support for research and graduate education-and for the graduate students.

\section{c. Trustees}

Even those trustees who clearly understand the importance of the research mission must find assurance that support for research will not, for example, result in tuition costs getting out of hand, potentially making college inaccessible for lower and middle-income families. Many trustees will be concerned that research is draining resources, including faculty time, from undergraduate education. Strong support for research by undergraduate and graduate students at trustee meetings is therefore crucial. Sharing relevant data with trustees and keeping them apprised of initiatives is, in my opinion, essential.

Some worry that trustees will be tempted to micro-manage if they have access to too much information. But if trustees don't have information, they may think there is something to hide, or that the administration doesn't have the information needed to make good management decisions. Indiana University has developed an extensive database on graduate students that includes information on progress 
toward degree and job placement, and we also maintain departmental data on faculty teaching and research productivity. These data are made available to the Board of Trustees when and as the President directs.

The Trustees were directly involved in our Strategic Directions program, which provided $\$ 20$ million in seed money for initiatives that were deemed valuable contributions to the university's missions and likely to be sustained in future years. The Trustees have also cooperated with the President in providing matching funds for endowed professorial chairs, as well as incentives for building a graduate student fellowship endowment. Individual trustees, as well as the Trustees as a group, have been very active in presenting the university's case to the legislature and to the executive branch. They have also consistently given new research initiatives the highest priority within the university. An example on our campus is the proposed $\$ 80$ million interdisciplinary Science Building.

\section{d. Citizens, alumni, parents}

One continuing initiative that has been successful for Indiana University is called Hoosiers for Higher Education (HHE). HHE is a large grass roots organization that recruits alumni to educate the general public about Indiana University and higher education issues, and mobilizes these volunteers to maintain contact with elected officials representing the district in which they reside. The point here is to organize, educate, and then use a large number of private citizens to carry the university research message $\nabla$ among other key messages in higher education $\nabla$ to others at the grass roots level.

e. Industry and venture capitalists

In addition to the usual partnerships with industry that arise from research or intellectual property transactions, universities also provide industry with a workforce of high quality. Further, a prestigious research university acts as a drawing card for attracting prospective employees to the state.

Some particular initiatives that we at Indiana University have found useful include:

IRLP. The Industrial Research Liaison Program provides business assistance and information services to Indiana's business and industrial communities, governmental units, and economic development agencies. These services include research and development assistance, proposal writing, and grant administration assistance; business and scientific information retrieval services; solutions to applied research problems; and opportunities for 
increased collaboration between Indiana University faculty and economic development organizations.

ARTI. The Advanced Research \& Technology Institute is a private, not-for-profit agent of Indiana University. In addition to the Indianapolis corporation headquarters, ARTI maintains offices in Bloomington and cooperates with faculty on all eight Indiana University campuses. By partnering through ARTI, Indiana businesses have access to the university's best strategists and scientists, cutting-edge laboratories, communication tools, and information technologies. ARTI helps put research and development to work in new and powerful ways that are both practical and economical.

Venture Capital Funds. Recently, a venture capital fund has been formed to invest in potential spin-offs of university research in the Midwest. The fund, already fully capitalized, is run by experienced and successful professionals in the venture-capital field, one of whom is a former vice president for finance at Indiana University.

We have decided to expand our economic development activities to include more opportunities for each of the Indiana University campuses to facilitate university partnerships with small and medium-sized businesses throughout the state and, when asked, to provide "white papers" for state policymakers.

f. State and federal elected officials and federal funding agencies

Indiana University has had an active on-going relationship with elected officials through our federal and state relations offices. I am sure your institutions do also. Our program is based on priorities set internally by a Federal Relations Committee, using a holistic approach that involves knowing the university's diverse strengths and priorities, and influencing federal legislation and agencies to fund programs that will strengthen both primary and emerging research areas. Program officers must know in detail that funds provided to Indiana University will result in excellent research, will be strongly leveraged by the university, and will most often result in sustainable programs so that a grant is not money wasted.

At the federal level, top university officials periodically visit the Indiana Congressional delegation in Washington regarding special requests for earmarks, most often involving research. We also ensure that university representatives are seen as national leaders in lobbying for more Congressional support for the federal funding agencies. This can best be done if our people have leadership roles in the national higher 
education associations such as the Association of American Universities, the National Association of State Universities and Land Grant Colleges, the Association of Graduate Schools, and the Council of Graduate Schools. I remember testifying on behalf of the National Science Foundation and the National Institutes of Health before a House committee with the directors of those two agencies on either side of me. This kind of opportunity has significant long-term advantages for the universities and the agencies involved.

At the state level, we utilize the various public stakeholders to supplement our vigorous state relations efforts. In this, as in other arenas, cooperation among higher education institutions in the state is crucial. In particular, common goals and initiatives involving Purdue University and Indiana University are important to both institutions.

We also use as many opportunities as possible to talk with legislators, trustees, and industry leaders about the importance of funding the research university, and the centrality of research to state economic development and quality of life. An example of such an opportunity is our annual Smithsonian Program, which brings legislators, trustees, business owners, and university personnel together in Washington, D.C. The invitees learn of opportunities for Indiana business around the world, visit several trade-important embassies for meals and discussion, and meet with the Indiana Congressional delegation.

I should mention here that Indiana University has a similar broadbased approach to fund raising from private corporations, foundations, and donors. But that's another talk, and would be better presented by other members of our administrative team, in particular Curt Simic, President of the Indiana University Foundation.

\section{Successes and Suggestions}

I'll mention just a couple of the recent successes Indiana University has had at the state level:

Twenty-First Century Fund. This fund, created in January 2000 by Indiana Governor Frank O’Bannon, provides \$25 million per year to nurture the state's growing research and development sector. In the first round of funding, more than $\$ 15$ million was awarded to 12 groups that partner Indiana universities and researchers with Indiana companies. An important point is that the creation of the Twenty-First Century Fund was urged and promoted by an independent Health Industry Forum; many of the projects that have received funding to date involve research on new health-related treatments and technologies. 
Proton Therapy Project. This project has received $\$ 10$ million from the state of Indiana and $\$ 2$ million from Congress. These funds will be used to create the Midwest Proton Radiation Institute, housed at the Indiana University Cyclotron Facility, to provide cancer treatment using advanced proton therapy techniques. This project was funded because of the efforts of external supporters who saw its benefit to citizens and its value as an economic development initiative.

\section{Questions for Future Consideration and Discussion}

I suggest that the questions listed below are helpful no matter what stage an institution is at in its development of the research mission. We all need to keep them in mind on a continuing basis. The questions also serve as an excellent ground for productive discussion within and among universities:

1. What are your recent outstanding successes? Failures? What do you learn from these efforts in terms of strategies for the future?

2. How accountable are you to your stakeholders and potential champions?

3. How do you currently use your faculty, students, parents, grass roots organization, alumni, trustees, industrial and other private sector leaders, federal and state relations team, and key state and federal legislators to influence others?

4. What resource, organization, or new initiatives are needed internally and externally to make a still better case for research support?

5. Does your institution sincerely use current research and public funds so that additional requests will be greeted with a sympathetic initial response?

6. Does your university aggressively cooperate with potential stakeholders?

\section{Conclusion}

I hope these remarks and questions will stimulate our discussion. In summary, before we can expect research to be higher on the public agenda we need to know and respond to the public's agenda for us. We 
must pay particular attention to the undergraduate learning environment and take the proper steps to improve it in tangible ways that allow stakeholders to see research as a positive contribution to teaching and learning (as opposed to a competitor to teaching). The understanding that we are mentors of the next generation of citizens whether we are teaching others in the classroom or in the research laboratory is crucial.

Of course, the reflective nature that is so necessary to teaching is also crucial in research and in cooperating with external stakeholders. The attitude of the faculty (the Ph.D. holders) as stewards of knowledge in their discipline (both in disseminating and creating new knowledge) could go a long way in creating a positive atmosphere in dealing with the improvement of the public's knowledge base and opportunities resulting from research. Then the public will be able and willing to "carry our water" more effectively than we could do ourselves and research will have a higher priority on the public agenda. 